\title{
Exploring Private Finance Initiative Implementation Issues in Malaysia Construction Projects: A Way Forward
}

\author{
Nor Suzila Lop, Kharizam Ismail, Haryati Mohd Isa, Natasha Khalil \\ Faculty of Architecture Planning and Surveying, Universiti Teknologi MARA, \\ Perak Branch, Seri Iskandar Campus, Seri Iskandar, 32610 Perak, MALAYSIA \\ norsu993@uitm.edu.my, khari511@uitm.edu.my, harya966@uitm.edu.my, natas582@uitm.edu.my \\ 017-316 7353
}

\begin{abstract}
Private Finance Initiative (PFI) was introduced in 2006 aimed at achieving value for money. Nevertheless, most of the PFI projects in Malaysia are currently facing difficulties in meeting the expectation. Therefore, a brainstorming workshop involving $69 \mathrm{PFI}$ practitioners from diverse backgrounds was conducted to investigate the implementation issues at the operational level and strategies towards achieving the project goals. The results showed that skills and knowledge, procedures and implementation, challenges in project management, and conflict on documentation were among the issues debated among workshop participants. "Loopholes" were identified to facilitate the improvement of the PFI project implementation in Malaysia.
\end{abstract}

Keywords: Operational Performance; Private Finance Initiative (PFI); Issues; Strategies.

eISSN: 2398-4287@ 2020. The Authors. Published for AMER ABRA cE-Bsby e-International Publishing House, Ltd., UK. This is an open access article under the CC BYNC-ND license (http://creativecommons.org/licenses/by-nc-nd/4.0/). Peer-review under responsibility of AMER (Association of Malaysian Environment-Behaviour Researchers), ABRA (Association of Behavioural Researchers on Asians) and cE-Bs (Centre for Environment-Behaviour Studies), Faculty of Architecture, Planning \& Surveying, Universiti Teknologi MARA, Malaysia.

DOI: https://doi.org/10.21834/ebpj.v5iSI3.2531

\subsection{Introduction}

Public-private partnership (PPP) procurement systems have been adopted extensively in construction projects around the world to achieve value for money (VFM). Although the importance of achieving good performance is often emphasized in the implementation of this procurement, there are still numerous projects that show a low level of performance especially involving social infrastructure projects. The growth of social infrastructure projects using PPP models should have a positive social impact on community development. This issue has raised questions concerning the rationale for adopting the PFI approach in Malaysia where VFM is a part of the goal to achieve success (Prime Minister Department, 2009).

Most of the previous studies in Malaysia have discussed the topic of procurement (Yusoff \& Xuen, 2013; Khaderi \& Aziz, 2010), risk allocation and assessment (Wang, 2011; Grimsey \& Lewis, 2002), success factor (Kahwajian et al., 2014; Ayesiga, 2013; Ismail \& Ajija, 2013), value for money (Ismail, 2013; Ismail, 2012), as well as performance measurement and monitoring (Liu et al., 2014; Yuan et al., 2009). Various insights on the problems and solutions for the PFI project's implementation have also been provided (Oktavianus \& Mahani, 2018; Yi et al., 2017; Hashim et al., 2017; Klijn \& Koppenjan, 2016). Yet, the implementation of PFI projects has continuously been challenging. Very limited studies have been conducted on the operational matters during the operational and

eISSN: 2398-4287@ 2020. The Authors. Published for AMER ABRA cE-Bsby e-International Publishing House, Ltd., UK. This is an open access article under the CC BYNC-ND license (http://creativecommons.org/licenses/by-nc-nd/4.0/). Peer-review under responsibility of AMER (Association of Malaysian Environment-Behaviour Researchers), ABRA (Association of Behavioural Researchers on Asians) and cE-Bs (Centre for Environment-Behaviour Studies), Faculty of Architecture, Planning \& Surveying, Universiti Teknologi MARA, Malaysia. DOI: https://doi.org/10.21834/ebpj.v5iSI3.2531 
maintenance (O\&M) phase. According to Lop et al. (2017), this is the most crucial stage because due to the lengthy period involved. Thus, there is a need to explore these issues within the O\&M phase because they will affect the success of the project implementation. Given the above points, this research presents the following two objectives: (1) to explore the issues and challenges and (2) to propose some strategies for improving the current PFI project's implementation.

\subsection{Method}

A brainstorming workshop was successfully held on 18 and 19 May 2017 at Universiti Teknologi MARA (UiTM), Shah Alam, Selangor. This workshop aimed to explore the current issues and challenges of the PFI project implementation during the O\&M phase. The participants were asked to recommend appropriate strategies as proactive actions to improve the implementation of operational PFI projects in Malaysia. A total of 69 PFI practitioners representing the project's clients, end-users, lawyers, auditors, and academicians were invited. To facilitate the cross-fertilization of ideas, the workshop participants were divided into five groups, each consisting of a good strategic mix of participants from various organizations and backgrounds. The data collected were then transcribed and analyzed using Atlas.ti@8 qualitative software. The findings are presented in a tabulation format.

\subsection{Result and Discussion}

The research findings are presented in two main sections: (1) the issues associated with the current PFI implementation and (2) strategies for improving the current implementation of PFI projects.

\subsection{The Issues Associated with the Current PFI Implementation}

Table 1 illustrates the feedback from the workshop's participants on the current issues of PFI implementation in Malaysia, particularly during the O\&M phase. Four major issues were revealed by them, namely (1) skills and knowledge on PFI, (2) procedures and its implementation, (3) challenges in PFI management, and (4) conflicts on documentation.

Table 1: Feedback on current issues of the PFI project's implementation in Malaysia

\begin{tabular}{|c|c|}
\hline Issues & Problems \\
\hline $\begin{array}{l}\text { Skills and } \\
\text { Knowledge of PFI }\end{array}$ & $\begin{array}{l}\text { Skills } \\
\text { - Lack of appropriate skills in managing PFI projects by the public and private sectors. } \\
\text { - Lack of bilateral communication between both clients and concessionaires. } \\
\text { Insufficient program or training to provide adequate knowledge of the PFI project's implementation among the } \\
\text { staff involved. } \\
\text { Knowledge } \\
\text { - } \quad \text { Lack of understanding and perception of work-related tasks among the staff. } \\
\text { - Inadequate knowledge transfer culture, as well as knowledge sharing among the staff, is involved. }\end{array}$ \\
\hline $\begin{array}{l}\text { Procedures and } \\
\text { Implementation }\end{array}$ & $\begin{array}{l}\text { Computerized Maintenance Management System (CMMS) } \\
\text { Monitoring Works } \\
\text { - } \quad \text { Plan Preventive Maintenance (PPM) works are difficult to monitor. There is an unclear mechanism on how to } \\
\text { impose penalty/demerit to the incomplete works. } \\
\text { Key Performance Indicators } \\
\text { - } \quad \text { Lacking methods for measuring KPIs for Plan Preventive Maintenance (PPM). } \\
\text { - Less understanding on the implementation of KPIs measurement-some of KPIs detailing is vague. } \\
\text { The percentage of the project's performance (using KPIs) presented by the concessionaire does not reflect } \\
\text { actual performance (physical) on site. It is due to the absence of an effective mechanism or tool to determine } \\
\text { the level of overall project's performance. } \\
\text { - There is an absence of weightage for the individual KPIs to show the most priority KPIs that affect a project's } \\
\text { performance (effect to monitoring work). } \\
\text { Work Performance } \\
\text { - Inconsistent work performance leads to poor performance achievement. }\end{array}$ \\
\hline $\begin{array}{l}\text { Challenges in PFI } \\
\text { Management }\end{array}$ & $\begin{array}{l}\text { Client/End User related issues } \\
\text { - } \quad \text { Constraints in terms of providing an adequate number of competent staff according to the expertise to manage } \\
\text { - } \quad \text { and monitor PFI projects. } \\
\text { incompetent concession holders. } \\
\text { - } \quad \text { Absence of long-term strategic plans prepared for the whole lifecycle project. } \\
\text { - Newly introduced policies that are sometimes difficult to understand in a short time. } \\
\text { - 'Lack of continuity' - there is no continuity involving the same person (client's team) from strategy stage, } \\
\text { procurement, design, construction to operation and maintenance in managing the project for the whole } \\
\text { lifecycle project. } \\
\text { Concessionaire related issues } \\
\text { - } \quad \text { Failed to provide enough manpower/staff to maintain and monitor the facilities. } \\
\text { - } \quad \text { Keep on changing the organizational structure of concession companies. } \\
\text { - Political interference and bureaucracy in project management }\end{array}$ \\
\hline $\begin{array}{ll}\text { Conflicts } & \text { on } \\
\text { Documentation } & \end{array}$ & $\begin{array}{l}\text { - The current Concessionaire Agreement document does not explicitly mention any sustainability clauses on it. } \\
\text { - }\end{array}$ \\
\hline
\end{tabular}


- Conflicts on documentation, weaknesses on existing procedures, and guidelines adopted.

- There is no "direct link" between KPI, demerit, and deduction (it is indirect)

\subsubsection{Skills and Knowledge on PFI}

Skills and knowledge are the essential elements in ensuring the success of a PFI project. However, in reality, lack of understanding, inappropriate skills, and inadequate transfer of knowledge in the implementation of PFI projects are the main issues faced by most of the practitioners in managing PFI projects. This shortcoming can be attributed to the difference in understanding between a concessionaire and a client in interpreting particular terminology and in determining the scope of work throughout a project's implementation. Another reason is the lack of exposure in terms of project implementation using the PFI approach among the practitioners involved. Besides that, the lack of communication and insufficient training provided to the public and private sectors can contribute to the failure of a project's implementation. Training or seminar is one of the best ways to deliver knowledge and skills to improve the efficiency of project implementation. Therefore, the government needs to take proactive actions in creating a knowledge culture and sharing of knowledge in addressing this problem. This measure appears to resonate the suggestions made by previous researches, who proposed that one of the obstacles to implementing successful PFls is the lack of knowledge and inadequate experience among practitioners in managing the project (Kipli et al. 2016; Chan et al. 2010; Li et al. 2005; and Zhang 2005).

\subsubsection{Procedures and Implementation}

The participants disclosed several barriers throughout the implementation of PFI projects, for instance, the lack of efficiency in the use of computerized maintenance management system (CMMS) for managing PFI projects, the difficulties in monitoring work, the lack of an effective performance measurement related to key performance indicators (KPI), and inconsistent work performance by the concessionaire. The most frequently debated issue addressed by the workshop's participants concerned about the implementation of $\mathrm{KPI}$. In a PPP/PFI approach, KPI is used as a tool for assessing the operational performance of a PFI project. Thus, the lack of effective KPls and methods of measurement constitute the most challenges in determining the level of project performance.

The circumstances mentioned above would lead to difficulties in calculating the percentage of performance achievement and in determining the amount of payment deduction. All these consequences can be attributed to unclear measurement parameters and a lack of detailed justification for KPls as stipulated in a concession agreement. As a result, KPI is difficult to be reached by a concessionaire. This shortcoming will in turn prompt the government's concern because the main objective of implementing PFIs, which is to attain VFM, is not achieved. Therefore, it is essential to have effective KPIs to ensure the success of a project's implementation throughout the life cycle of the projects (Lop et al. 2017). The issues raised from this workshop are therefore in line with the view of several scholars by Liu et al. (2014); Yuan et al. (2009) and Lop et al. (2018) who stressed on the importance and usefulness of KPIs in determining the level of project performance. The view is also supported by Ali Javed et al. (2013) who quoted that, Australia as one of the countries experiencing similar issues as Malaysia concerning KPI implementation in PPP projects.

\subsubsection{Challenges in PFI Project Management}

The challenges in PFI management are also among the crucial issues discussed among the workshop participants. The issues identified were alienated into client-related issues and concession-related issues. Client-related issues and concessionaire-related issues are geared toward managing resources (manpower). The majority of the participants revealed that the insufficiency of competent staff in managing PFI projects is one of the reasons causing poor project management. This is due to the frequent exchange of staff members within an organization both in the private and government sectors. The staff members responsible for managing the PFI project are also non-permanent from the first phase (strategy formulation phase) to the final phase of the project (O\&M). Such a case indicates no continuity in terms of work tasks throughout a project's lifecycle. Thus, the involvement of different staff members across project phases in managing a PFI project will significantly affect the project progress. In reality, most of the staff members are less focused on their job scope even though their organization provides adequate staff to manage PFI projects. These staff members have nevertheless been burdened by the variety of unrelated scope of work. Therefore, both the private and government sectors should discover an initiative to ensure that the performance of the PFI projects is not affected by this factor. Thus, the availability of competent personnel to manage PFI projects is the most important cross-cutting factor to success. This measure resonates with the suggestion by Ayesiga (2013) who agreed on the importance of the involvement of competent individuals in managing PFI projects.

\subsubsection{Conflicts on Documentation}

Conflicts on documentation can be demarcated as discrepancies that occur among other documents. This situation is due to the weaknesses of the existing procedures and the guidelines used in managing PFI projects. Several "gray areas" have been noted in the PFI documents particularly those related to the agreements and procedures. It has been a big challenge for the public and private stakeholders to handle the conflict. Another issue pointed by the participants is the difficulty in assessing information because all the data are not kept systematically. Most of the documents are kept in a printed copy by certain individuals. There is no centralized storage of data that can be easily referred to by the project parties. On the same note, Hardcastle et al. (2006) stressed that proper recording, archiving, and referencing of documents will ease a project's implementation.

From the findings, it can be concluded that the majority of the participants agreed that the current PFI practice in Malaysia is still inadequate and incomprehensive in terms of project implementation strategies. All the issues highlighted in this workshop will 
significantly affect the operational performance of PFI projects and simultaneously lead to projects failure. Therefore, actions need to be taken to ensure that all the problems can be overcome without affecting the operational performance and VFM of the projects.

\subsection{Strategies for Improving the Current PFI Projects' Implementation}

The workshop's participants were also asked to recommend the appropriate strategies to improve the current implementation of PFI projects and the findings are summarised in Table 2. A few strategies were recommended by the participants to improve the effectiveness of the implementation of current PFI projects. The suggestions were grouped into four themes: (1) the use of an updated system, (2) comprehensive documentation, (3) encouraging knowledge sharing culture, and (4) provision of sustainability elements in a concession agreement.

Table 2: Feedback on the strategies to improve the current PFI projects' implementation

\begin{tabular}{|c|c|c|}
\hline \multicolumn{3}{|r|}{ Proposed Strategies } \\
\hline & $\begin{array}{l}\text { The Use of } \\
\text { Updated System }\end{array}$ & $\begin{array}{l}\text { - The CMMS system needs to be transformed into an integrated application for more organized } \\
\text { output and be fully utilized. } \\
\text { - The audit trail on the data derived from the CMMS system needs to be regularly done to ensure } \\
\text { that the data is genuine and transparent. } \\
\text { - Benchmarking of CMMS systems from other projects to improve the current system. } \\
\text { - Access to the system should be user friendly. } \\
\text { - Create an online system as a database for all information about operational issues between all } \\
\text { staff involved in PFI projects. }\end{array}$ \\
\hline 2. & $\begin{array}{l}\text { Comprehensive } \\
\text { Documentation }\end{array}$ & $\begin{array}{l}\text { - Documents need to be stored efficiently or be easily accessible information center (resource } \\
\text { center, online system) - easy to manage. } \\
\text { - The format for reporting performance, payment, and work execution schedule should be } \\
\text { following the agreement for easy monitoring purposes. } \\
\text { - Provide easy and clear Standard Operating Procedures (SOP) and this should be in line with the } \\
\text { PFI project implementation. } \\
\text { - The existing KPIs need to be refined and transparent to avoid misunderstanding among both } \\
\text { parties. }\end{array}$ \\
\hline 3. & $\begin{array}{l}\text { Encourage } \\
\text { Knowledge } \\
\text { Sharing Culture }\end{array}$ & $\begin{array}{l}\text { - Knowledge sharing culture is helpful in problem-solving, decision-making, and continuous } \\
\text { learning processes. } \\
\text { - Knowledge sharing can also improve the quality of work and indirectly promote innovation and } \\
\text { creativity in carrying out work. } \\
\text { - The client needs to be knowledgeable and needs to participate during the entire PFI projects. }\end{array}$ \\
\hline 4. & $\begin{array}{l}\text { Provision of } \\
\text { Sustainability } \\
\text { Elements in the } \\
\text { Concession } \\
\text { Agreement }\end{array}$ & $\begin{array}{l}\text { - The implementation of sustainability elements must reflect cost savings in all life cycle stages. } \\
\text { - Provide a policy that requires all government projects to comply with the sustainability policy in } \\
\text { - PFI projects. } \\
\text { - Researchers need to identify the benefits of sustainable technologies in the long run cycle of the } \\
\text { projects. }\end{array}$ \\
\hline
\end{tabular}

\subsubsection{The use of Updated System}

As mentioned earlier, the lack of an efficient system and strategy in managing PFI projects are described as one of the crucial issues that need to be addressed. Thus, the government needs to take a few initiatives to overcome these issues. A few of the participants suggested that the current CMMS system needs to be transformed into an integrated application, for example, Building Information Modeling system, for a more easily manageable and organized output. The users also are encouraged to fully utilize the CMMS system to ensure full coverage of maintenance is manageable. This is in line with Muzani Mustapa (2013) stated that a strategic approach in maintenance works related to the use of an effective computerized system is suggested. This suggestion can help the organization to expedite the process of managing the facilities. Also, it can assist the staff in-charge of executing the jobs effectively by making informed decisions with the use of the right tools.

\subsubsection{Comprehensive Documentation}

Comprehensive documentation is also highlighted by the workshop's participants. The documents of a PFI project, such as official information or evidence that serves as a record, need to be stored efficiently. A resource center or an online system database needs to be established to ease the participants of a project to retrieve information. Besides, there is also a need for a proper filing of all related project documents to avoid misunderstanding and misinterpretation among the project parties (Hardcastle et al., 2006).

\subsubsection{Encouraging a Knowledge-sharing Culture}

Knowledge sharing practices, decision-making, and continuous learning processes should constitute a culture in PFI organizations. This strategy is also recommended by most of the participants as a means to ensure that all information is delivered correctly. The measure can also improve the quality of work by indirectly promoting innovation and creativity in performing their tasks. Correspondingly, such a strategy has been mentioned by Hashim et al. (2017) who contests that human factors are among the aspects that should be emphasized for the betterment of a PFI project's implementation. 


\subsubsection{Provision of Sustainability Elements in a Concession Agreement}

The participants also suggested that the elements of sustainability be included in a PFI contract to resolve defect issues inherent in the projects. It is essential to ensure that the projects will sustain in twenty to thirty years of the concession period to fulfill the government's agenda of sustainability. This purpose is also mentioned by Hill and Collins (2004) who stated that the whole life costs of PFI projects on maintaining the asset should be considered during the design and construction phase. Concurring with this is the view of Shen et al. (2016) who stressed the importance of implementing sustainability in PFI projects to ensure cost-saving and achieve VFM.

\subsection{Conclusion}

Exploring the current issues and challenges is one of the most important endeavors to prevent PFI project failures. Therefore, the adequacy and completeness of PFI procurement during the project's implementation is one of the strategies that will affect the success of the project. Findings from the workshop conducted have uncovered the loopholes in the current PFI projects' implementation in Malaysia. More can be learned by the industry from the issues and challenges identified. The study thus addresses an urgency for the stakeholders to review the existing system by considering the strategies for the betterment of PFI projects implementation. In other words, the strategies proposed during this workshop provide a good platform for changes. The results of this research can also serve as preliminary findings concerning the deficiencies and weaknesses in the implementation of PFI. The strategies addressed can facilitate more comprehensive research to be conducted in the future and form a basis of valuable guidelines, particularly for the public and private sectors in Malaysia.

\section{Acknowledgment}

The authors would like to thank all the workshop's participants for spending their valuable time to participate in this workshop and the provision of vital information. Comments of the anonymous reviewers were very helpful and are gratefully acknowledged. The authors are also grateful to the Centre of Postgraduate Studies, Universiti Teknologi MARA, Perak Branch for the support of this research study. The research is also funded by "Special Grant Incentive for Supervision in Perak" (GKIPP) Phase 1/2018.

\section{References}

Ali Javed. A., Patrick T.I. Lam and Patrick X.W. Zou. (2013). Output-based specifications for PPP projects: Lesson for facilities management from Australia. Journal of Facilities Management, 11(1), 5-30.

Ayesiga, R. (2013). Success Factors for the Implementation of Public-Private Partnerships in the Construction Industry in Uganda, 18(2), 1-14.

Chan, A. P. C, Lam, P. T. I., Chan, D. W. M., Cheung, E., and Ke, Y. (2010). Potential Obstacles to Successful Implementation of Public-Private Partnerships in Beijing and the Hong Kong Special Administrative Region. Journal of Management in Engineering, 26(1), 30-40.

Grimsey, D., \& Lewis, M. (2002). Evaluating the risks of public-private partnerships for infrastructure projects. International Journal of Project Management, 20(2002) 107-118.

Hardcastle, C. Edwards, P.J., Akintoye, A., and Li, B. (2006). Critical success factors for PPP/PFI projects in the UK construction industry: A critical factor analysis approach. In T.S. Ng (ed.). Public-Private Partnerships: Opportunities and Challenges. Hong Kong: Centre for Infrastructure and Construction Industry Development, University of Hong Kong, 75-83.

Hashim, H., Che-Ani, A. I., \& Smail, K. (2017). Public-Private Partnership (PPP) Project Performance in Malaysia: Identification of Issues and Challenges. International Journal of Supply Chain Management, 6(2), 265-275.

Hill, J., Collins, J., (2004). PFI: Meeting the sustainability challenge. Green Alliance.

Ismail, S., and Aijia, Sh. R. (2013). Critical Success Factors of Public-Private Partnership (PPP) Implementation in Malaysia. Asia-Pacific Journal of Business Administration, 5(1), 6-19.

Ismail, K. (2012). A Value for Money Assessment Framework for Public-Private Partnership Approach. Ph.D., Thesis. Malaysia.

Ismail, S. (2013). Drivers of value for money public-private partnership projects in Malaysia. Asian Review of Accounting, 21(3), 241-256

Kahwajian, A., Baba, S., Amudi, O., \& Wanos, M. (2014). Identification of Critical Success Factors (CSFs) for Public-Private Partnership (PPP) Construction Projects in Syria, Jordan Journal of Civil Engineering, 8(4), 393-405.

Khaderi, S. S., \& Aziz, A. R. A. (2010). Adoption of Private Finance Initiative (PFI) in Malaysian Public Works Projects: Are We Ready? ClB TG72 World Building Congress, 105-120.

Kipli, K., Prof, A., Fadhlin, S., \& Mustafa, F. D. (2016). The Missing Point of Knowledge Management in PFI Projects, 25, 1-11.

Klijn, E. H., \& Koppenjan, J. (2016). The impact of contract characteristics on the performance of public-private partnerships (PPPs). Public Money \& Management, 962(36:6), 455-462. 
Li, B., Akintoye, A., Edwards, P. J., and Hardcastle, C. (2005). "Perceptions of Positive and Negative Factors Influencing the Attractiveness of PPP/PFI Procurement for Construction Projects in the UK: Findings from a Questionnaire Survey". Engineering, Construction, and Architectural Management, 12(2), 125-148.

Liu, J., Love, P. P. E. D., Smith, J., Regan, M., \& Davis, P. R. (2014). Life Cycle Critical Success Factors for Public-Private Partnership Infrastructure Projects. Journal of Management, 1-7.

Lop, N. S., Ismail, K., \& Isa, H. M. (2017). The Implementation of Key Performance Indicators in the Malaysian Private Finance Initiative Projects. EnvironmentBehaviour Proceedings Journal, 2(5), 95.

Lop, N. S., Ismail, K., \& Isa, H. M. (2018). The Execution of Key Performance Indicators in the Operational Phase of PFI Projects in Malaysia. Asian Journal of Quality of Life (AjQoL), 3(12), 157-167.

Muzani Mustapa. (2013). Facilities management knowledge in private finance initiative (PFI) healthcare projects. Ph.D., Thesis. Malaysia.

Oktavianus, A., \& Mahani, I. (2018). A Global Review of Public-Private Partnerships Trends and Challenges for Social Infrastructure, 6001(147), 1-9.

Prime Minister Department. (2009). Public-Private Partnership (PPP) Guideline, 1-12.

Shen, L., Tam, V. W. Y., Gan, L., Ye, K., \& Zhao, Z. (2016). Improving Sustainability Performance for Public-Private-Partnership (PPP) Projects.

Wang, N. (2011). Risk Allocation in the Operational Stage of Private Finance Initiative Projects. Journal of Performance of Constructed Facilities, 25(6), 598-605.

Yi, X., Gong, Q., \& Zhao, H. (2017). A Literature Research on the Hot Issues in Public-Private Partnership Projects: Based on the Classified Statistics of Literatures During 2008-2016. International Conference on Economics and Management Engineering, 90-94.

Yuan, J., Zeng, A. Y., Skibniewski, M. J., \& Li, Q. (2009). Selection of performance objectives and key performance indicators in public-private partnership projects to achieve value for money. Construction Management and Economics, 27(3), 253-270.

Yusoff, W. Z. W., \& Xuen, J. W. M. (2013). Private Finance Initiative (PFI)/ Public-Private Partnership (PPP) in Malaysia context. International Journal of Information Technology and Business Management, 17(1), 29-42.

Zhang, X. (2005). Paving the Way for Public-Private Partnerships in Infrastructure Development. Journal of Construction Engineering and Management, 131(1), 71-80. 